\title{
Política criminal sem preocupações metafísicas $(*)$
}

\author{
Noé Azevedo \\ (Professor de Direito Penal da Faculdade de \\ Direito da Universidade de São Paulo)
}

As concepções filosóficas e jurídicas sôbre a organização e a defesa da sociedade evoluem, como tudo neste mundo, mas essa evolução está subordinada a um processo muito lento. Mesmo no direito penal, onde as mutações são mais rápidas, as idéias novas só se impõem depois de discussões, que se prolongam por decênios e avançam pelo século adentro.

Assim, a passagem do classicismo para o positivismo já vai consumindo três quartos de século. Desde os tempos mais remotos assinalados pela história do progresso humano, a reação dos grupos sociais, ou da sociedade já definitivamente organizada, contra o crime sempre se manifestou por uma tendência punitiva, consistente na imposição ao delinqüente de um mal mais ou menos equivalente ao que êle causara à sua vítima direta, ou ao corpo social.

(*) Aula de encerramento do ano letivo de 1950 da Faculdade de Direito da Universidade de São Paulo. 


\section{Função educatíva "versus" função punitiva}

Chega-se agora a uma fase em que grandes criminalistas começam a cogitar francamente da abolição de tôda idéia punitiva nessa reação. De há muito, já, as conferências e congressos penais e penitenciários vêm afirmando que a finalidade principal da pena deve ser educativa, visando a reforma do delinqüente e a sua readaptação ao meio social. Mas os grandes criminalistas da atualidade começam a se impressionar com o fracasso das tentativas que a ciência penitenciária tem feito no sentido de reunir duas finalidades conflitantes, naquilo que modernamente se chama de tratamento dos delinqüentes. O remédio que o velho direito penal prescrevia para êsse tratamento era a pena. Mas a pena, através da sua longa história, veio sempre desempenhando uma função degradante, tendente a eliminar ou segregar o criminoso da sociedade e a atrair contra o mesmo a repulsa da gente ordeira e honesta.

Por isso, o pensamento novo, visando imprimir a êsse tratamento penal uma função educativa, que importaria mais em um benefício do que num sofrimento para o condenado e que, em vez de carrear para o mesmo a antipatia da comunidade social, deverá provocar um sentimento de solidariedade humana, constitui um ideal de realização muito difícil, enquanto mantiver êsse propósito de reunir finalidades contraditórias em sua atuação.

Em nosso estudo sôbre "A Socialização do Direito Penal", feito em 1927, mostramos que as reformas penais até então propostas eram orientadas pelo pensamento da Escola Positiva, de pôr em primeira plana o delinqüente e em segunda o delito. 0 tratamento penal não devia consistir na dosagem de um mal a ser infligido ao delinqüente, proporcional ao que êle causara. O seu objetivo 
principal tinha de ser o da reeducação do criminoso e sua conseqüente reintegração no ambiente social.

$O$ projeto Ferri fôra organizado com essa dupla finalidade. Na sua exposição de motivos, o Ministro Mortara dizia o seguinte:

“A defesa da organização jurídica contra o delito deve ser praticada não só com medidas de sábia e previdente prevenção, como também por meios repressivos. Estes devem ser adaptados com claro discrime a um duplo fim. Para a maioria dos delinqüentes ocasionais, que não tenham sido impelidos ao crime por motivos ignóbeis, convém estudar e aplicar um tratamento humanitário, capaz de preservá-los da reincidência e de facilitar-lhes a reabilitação e a volta pronta a útil cooperação no convívio social.

"Para a criminalidade de caráter verdadeiramente habitual, convêm as medidas idôneas para eliminar do meio honesto êsses elementos pervertidos, que nêle exercitam, fatalmente uma ação desagregadora e perversiva.

"Experiência de trinta anos prova a insuficiência da legislação atual para êsse árduo escopo; é pois oportuno sujeitá-la uma larga revisão, a fim de que a defesa contra a delinqüência habitual se coordene racionalmente com um sistema geral que leve em conta principalmente as condições pessoais do delinqüente, mais que as da materialidade dos atos delituosos."

\section{A contradição nos códigos penais}

O projeto Ferri foi substituído pelo denominado Rocco, no qual se nota a presença das duas preocupações contraditórias. O Código Penal italiano de 1930, resultante dêsse projeto, realizou a fusão das duas escolas. Quis ser, ao mesmo tempo, um Código repressivo e preventivo. Baseou 
a repressão na imputabilidade moral, dosando as penas pela intensidade do dolo. Fundou a prevenção na periculosidade revelada pelo delinqüente através do delito, e cuidou de combater essa periculosidade não sòmente com a pena, mas também com as medidas de segurança.

Adotamos êsse sistema, em nosso Código de 1940. Vários outros Códigos modernos instituíram as medidas de segurança. Mas o que se observa, nestes vinte anos de experimentação, é uma verdadeira involução do instituto das medidas de segurança, que - talvez pela falta de estabelecimentos adequados para o seu cumprimento - conservaram os mesmos característicos de tratamento aflitivo das penas pròpriamente ditas. Em vez do sistema penal evoluir, transformando-se em tratamento benéfico do delinqüente, com predominância das medidas de segurança, como que regrediu, notando-se uma reação, de natureza marcadamente penal, em duas fases.

\section{A fôrça dos preconceitos}

Isso provém da circunstância de que a sociedade ainda não conseguiu vencer milenária antipatia despertada pelos delinqüentes, nem mudar a atitude de hostilidade que sempre manteve para com os mesmos, sendo êsses preconceitos mais fortes do que os impulsos humanitários despertados pelos novos credos filosóficos.

Entretanto, com relação aos delinqüentes menores, as leis de quase todos os povos civilizados já consagraram: um sistema predominantemente tutelar e do qual já se pode considerar abolida, tanto na teoria como na prática, tôda idéia de punição.

Naquele trabalho de 1927, fazíamos as seguintes considerações e sugestões: 
"Por que é, então, que os Códigos de Menores já não cogitam de penas, contentando-se com prescrever medidas que, amparando os menores delinqüentes e abandonados, realizem o escopo da defesa social?

"Não é difícil a explicação. A evolução de tôdas as idéias encontra sempre resistência nos preconceitos arraigados na mentalidade do público, pelas práticas ou usos tradicionais. Mas as idéias-fôrças vão rompendo as dificuldades. E, para transpor os escolhos, as correntes sempre se encaminham para os pontos mais fáceis de romper. O lado sentimental tem sempre uma influência decisiva na propagação das novas doutrinas. Tôda a legis. lação social moderna tem aparecido de envolta com manifestações de ordem sentimental. Ora são as mulheres que trabalham em oficinas, que despertam a comiseração, exigindo medidas protetoras para o seu estado; ora são os menores que inspiram leis que impeçam a sua exploração nas fábricas; e ora são os desprotegidos da fortuna, ameaçados pelos senhorios de ficar ao relento, que tangem com a sua penúria a corda sentimental dos legisladores, determinando a promulgação das chamadas leis do inquilinato. São sempre os fracos que despertam êsses sentimentos piedosos, em atenção aos quais cedem os homens de princípios. E' o sentimentalismo que rompe os preconceitos. Não fôsse o lado sentimental e as novas doutrinas sôbre o tratamento dos menores ainda não teriam triunfado sôbre os preconceitos da velha escola."

\section{Aplicação ampla da teoria da periculosidade}

"Em relação aos menores, já se faz a mais ampla aplicação da teoria da periculosidade. Tanto os que já cometeram faltas ou crimes, como os que ainda não delin- 
qüiram, ficam sujeitos às medidas de proteção e amparo, criadas pelo legislador. Internam-se tanto os menores delinqüentes como os abandonados, que se acham em estado perigoso.

"Não há razão científica que determine procedimento diverso em relação à periculosidade dos maiores. 0 que o novo direito penal tem em vista é a defesa da sociedade contra a ação de indivíduos perigosos. Pouco importa que êles já tenham delinqüido ou não; desde que se revele por qualquer modo a periculosidade, deve o Estado tomar as necessárias medidas de precaução, dando aos indivíduos perigosos o tratamento necessário para evitar que venham a causar danos aos seus semelhantes.

“A resistência contra essa ampliação do conceito da periculosidade, oposta pelos escritores que ainda se sentem presos aos dogmas do classicismo penal, é a manifestação mais evidente do individualismo da velha escola. O Estado não tinha direito de punir ou de sujeitar a qualquer tratamento um cidadão que não houvesse cometido falta alguma. $\mathrm{O}$ absoluto respeito à liberdade do indivíduo é um dos dogmas filosóficos do direito individualista. Sem que o cidadão cometa alguma falta ninguém pode tocar na sua pessoa, nem obrigá-lo a fazer aquilo que não seja do seu agrado.

"Mas êsse individualismo já não existe no mundo contemporâneo. As idéias socialistas vão penetrando dia a dia no direito de todos os povos. O que se dá com relação ao direito privado, verifica-se também no campo de ação do direito penal. Assim como no direito civil e no direito comercial o interêsse social vai prevalecendo sôbre as prerrogativas individuais, também no direito penal a necessidade da defesa social impõe o sacrifício da liberdade dos indivíduos, mesmo quando êstes não tenham cometido falta alguma que justifique a ação do Estado. 
“Esta não é determinada pela falta do individuo, mas pela sua periculosidade. A doutrina que transformou $o$ procedimento penal dos menores em tratamento há-de operar igual transformação quanto aos adultos.

"Assim como se trata de menores perigosos, quer sejam delinqüentes, quer se achem simplesmente abandonados ou em estado perigoso, também se há-de tratar dos adultos que se revelam perigosos, quer pela prática de um delito, quer por uma circunstância qualquer, pois não é a falta ou crime que justificam a ação ou reação do Estado, e sim a necessidade da defesa social."

\section{Opiniões recentes: Congresso de Haia}

Transcrevemos estas páginas porque o assunto que elas focalizam foi objeto de teses discutidas no Congresso PenaI e Penitenciário de Haia e no Congresso de Criminologia de Paris, realizados em agôsto e setembro do corrente ano.

Na Holanda, discutiu-se a seguinte tese:

"Certaines expériences faites dans le traitement de la jeunesse délinquante ne devraient-elles pas être étendues au traitment des délinquants adultes?"

Foi relator geral o professor Giuliano Vassalli, da Universidade de Gênova, que se baseou nos relatórios parciais do Prof. Nico Gunzburg, da Bélgica; de Kai Borgsmidt, da Dinamarca, de Glenn M. Kendall, dos Estados Unidos, de Jean Pinatel, da França, de Falcone Lucifero e Guido Colucci, da Itália, de W. P. J. Pompe, da Holanda, de Margery Fry, da Inglaterra, de Gunnar Thurén, da Suécia, e de H. R. Gautschi, da Suíça.

A conclusão votada pela $4 .^{\text {a }}$ Seção do Congresso e aprovada pela Assembléia Geral, em sua substância, reza o seguinte: 
"A Seção constata que, nos dois domínios - Luta contra a criminalidade dos adultos e luta contra a delinqüência juvenil - uma evolução gradual se opera, tendendo a substituïr o tratamento punitivo pelo corretivo, na luta contra a criminalidade e a delinqüência. Por diversas razões, progressos mais substanciais têm sido realizados, nesse sentido, no domínio do tratamento da juventude. Eis por que é desejável inspirar-se nos métodos de tratamento da juventude para dai tirar sugestões e orientações aplicáveis ulteriormente na luta contra a criminalidade. A Seção entende que muitos dos adultos são suscetíveis de se beneficiar com a formação e com as possibilidades reservadas nos vários países aos menores sòmente. Não é porque um jovem ou uma jovem sejam de maior idade aos olhos da lei que devam ser condenados a uma forma de prisão que arrede tôda probabilidade de educação, de formação e de reforma. Ém particular, a Seção entende que as experiências adquiridas no domínio da delinqüência infantil, no que concerne à constituição do "dossier" da personalidade, aos sistemas de prova ("probation"), à liberdade vigiada e ao perdão judiciário, d'everão ser aplicadas igualmente no domínio da criminalidade dos adultos."

A idéia predominante nos relatórios parciais é a de considerar os jovens delinqüentes sujeitos aos benefícios da legislação de menores, não só os de menos de 18 anos, como todos os que ainda não atingiram a maioridade legal, sendo que alguns dos relatórios propunham mesmo a aplicação dêsse regime tutelar a todos os delinqüentes de menos de 25 anos.

Se corrermos as estatísticas criminais de todos os países do mundo, veremos que a maioria dos delinqüentes é formada por jovens dessa idade. $\mathrm{E}$, assim sendo, temos como vencedora aquela idéia, manifestada em 1927, de se aplicar a política criminal dos menores também aos adul- 
10s, sujeitando-os a um regime tutelar eminentemente preventivo e caracterizado por medidas protetoras, providências benéficas, e não por penalidades, substituindo-se os cárceres, as prisões, as penitenciárias e até mesmo os reformatórios do antigo sistema, pror escolas, organizadas de acôrdo com os métodos pedagógico-cientị́ficos, e estabelecimentos de tratamento físico, moral e mental de todos os internados ou abrigados.

\section{Congresso de Criminologia de Paris}

No Congresso de Criminologia de Paris, o Professor argentino Oswaldo Loudet focalizou o problema do estado perigoso sem delito, mostrando que a parte mais fecunda da doutrina da periculosidade ficara sem nenhum efeito, em virtude das disposições dos novos Códigos, que só permitem a aplicação de medidas de segurança "post delictum". O respeito às liberdades individuais, apregoado por cento e cinqüenta anos de democracia, ainda não permitiu que a liberdade do cidadão seja restringida, sem que êle tenha dado causa a isso, por um procedimento que importe em infração da lei penal, quer pela prática de um crime, quer pela de uma contravenção reveladora de periculosidade.

Ainda que se diga que as medidas de segurança não constituem pena e que devem representar um benefício para o paciente, o fato é que elas importam em restrições da liberdade, ora pelo internamento em casa de custódia e tratamento, ora em manicômio judiciário ou, ainda, em colônias agrícolas e outros estabelecimentos, redundando tudo em modalidades novas de aprisionamento.

Estranhava o professor argentino essa resistência da doutrina e da prática, contra a implantação de métodos de tratamento que devem ser realizados de maneira a con:- 
jugar o objetivo da defesa social com o da cura do próprio paciente, quando ela seja possivel, ou com o de uma assistência caracterizadora d'a mais perfeita solidariedade humana, quando se trate de incuráveis ou de inơivíduos abso lutamente inadaptáveis ao meio social.

Sendo um psiquiatra, habituado a observar o que ocorre no setor da sua especialização, não podia explicar por que é que os legisladores, até agora, não permitiram o internamento de indivíduos manifestamente perigosos, em virtude de constituição psicopática, afecção mental ou devastação cerebral produzida pelo álcool ou entorpecentes, antes que os mesmos tenham praticado algum malefício, pois que, tratando-se de pessoas irresponsáveis, não se pode basear em sua culpa a reação da sociedade ou a providência a ser tomada.

Assim como se internam nos hospícios e sanatórios milhares de indivíduos, que aí são conservados durante anos seguidos e às vêzes por tôda a vida, com base em simples prescrições dos médicos da família e dos psiquiatras dos estabelecimentos, sem que êsses individuos tenham praticado infrações das leis e regulamentos, poderiam ser adotadas medidas de segurança, independentemente da verificação de crimes ou de contravenções, a ser feita de maneira solene por sentenças das autoridades judiciárias.

Para evitar abusos, poder-se-ia redigir um Código preventivo, estabelecendo normas, meticulosas e precisas, para fundamentar o diagnóstico do estado perigoso, a ser verificado pelos psiquiatras e declarando pelas autoridades judiciárias.

\section{Resistência passiva contra a prevenção}

Nada mais lógico e razoável. Entretanto, observa-se uma resistência dificilmente removível contra essas medi- 
das, tendentes a promover a defesa da sociedade pela via preventiva, em vez de se valer o Poder Público dos velhos métodios e precessos da justiça repressiva, que não consegue reparar o mal já praticado nem prevenir o mal futuro, por ser hipotético o poder intimidativo das penalidades.

Essa resistência é explicada pela fôrça tremenda da inércia que se observa na evolução d'as instituições sociais, inércia que se manifesta pela subsistência das velhas idéias e preconceitos, subsistência essa que provém, muitas vê. zes, de interêsses que viriam a ser contrariados com o advento de novas práticas.

Assim, quanto à prisão, perduram os preconceitos de que os sofrimentos que a mesma inflige aos condenados concorrem não só para a sua reabilitação, pela expiação do mal praticado, como ainda exercem influência intimidativa de ordem geral, afastando da senda delituosa inumeráveis delinqüentes em estado potencial.

Os penitenciaristas modernos confessam a impossibilidade de se reunirem no tratamento dos criminosos os dois efeitos contraditórios visados pelos códigos ainda em vigor, isto é, o de punir e o de reabilitar o d'elinqüente. As penas, entretanto, vão sendo lentamente eliminadas da política criminal contemporânea.

Donnedieu de Vabres, no seu pequeno grande livro "La Justice Pénale d'aujourd'hui", faz uma enumeração de penas que êle classifica como penas do passado, por terem sido abolidas diante da repulsa manifestada pelos sentimentos dos povos civilizados contra a sua crueldade. Assim, estão extintas as penas corporais, as mutilações, as marcas a fogo, os açoites e outras práticas infamantes. Mas entre essas penas corporais ainda se conservam as de morte e de prisão. 
Abolição da pena de morte

Quanto à primeira, diz o grande professor francês que a sua evolução se assinala por uma acelerada marcha para a supressão. Nota que, ao lado do movimento abolicionista, que levou muitos Códigos a suprimi-la de uma vez, há uma tendência marcada para a sua restrição, nas legislações que ainda a conservam. E' prescrita com extraordinária parcimônia para poucos crimes, de gravidade extrema. E, mesmo com relação a êsses delitos, ela é aplicad'a cada vez menos pelos tribunais. Quando imposta, ainda fica sujeita às comutações pelo Poder Executivo.

Faz uma estatística dessa aplicação, na França e em outros países, com o que se evidencia a asserção de que dentro em breve a pena de morte será também uma das penas do passado.

\section{A pena de prisão}

Quanto à pena de prisão, o movimento abolicionista vem ganhando numerosos adeptos, tomando agora um impulso que se pode dizer decisivo. A seu respeito, pode-se descrever também aquela marcha acelerad'a para a supressão, que caracteriza a evolução da pena de morte, segundo a feliz imagem do professor francês.

Os inconvenientes da prisão foram postos à mostra, em primeiro lugar, quanto às prisões em comum e, em segundo, quanto às prisões de curta duração.

Para evitar os malefícios da promiscuidade que se observava nas antigas prisões em comum, inventou-se o sistema celular, que durante muito tempo prendeu a atenção do mundo. Para desmoralizar a pena de curta duração, bastou o libelo genial traçado por Anatole France, no 
seu "Crainquebille". De há muito, porém, já vinham os penalistas cuidando da sua substituição. Na própria França, surgiu nos fins do século passado, a lei Béranger, sôbre o "sursis", cuja finalidade precípua está em evitar o recolhimento à prisão dos delinqüentes primários condenados a penalidades que não chegam para produzir hábitos de vida morigerada, mas são mais do que suficientes para corromper delinqüentes ocasionais. Como disse certa vez Plínio Barreto, em frase de sabor anatoliano, entra para cadeia um inocente e daí sai, ao cabo de poucos meses, criminoso nato. .

\section{Os inconvenientes da prisão curta}

Ainda agora, constituiu objeto de estudo no $12 .^{\circ}$ Congresso Penal e Penitenciário a seguinte tese:

"Les courtes peines d'emprisonnement et leur remplacement par d'autres mesures (mise à l'épreuve, amende, travail à domicile, etc.)"

O relatório geral foi feito pelo penitenciarista Hardy Göransson, da Suécia, tendo como fontes informativas os estudos apresentados por Pierre van Drooghenbroeck, da Bélgica, Jaroslav Pauk, da Tchecoslo'váquia, Jorgen Trolle, da Dinamarca, Yvonne Marx, da França, Arturo Santoro, da Itália, Ni. Muller, da Holanda, Johannes Andenaes, da Noruega, Gerhard Simson, da Suécia, A. Luisier, da Suíça, Herman Mannhein, da Inglaterra, e Joseph P. Murphy, dos Estados Unidos.

Discutido o assunto na $3 .^{a}$ Seção, ofereceram seùs numerosos componentes as seguintes conclusões para deliberação da Assembléia Geral:

“O 12. ${ }^{\circ}$ Congresso Penal e Penitenciário constata, uma vez mais, os graves e numerosos inconvenientes das curtas penas de prisão. Condena o uso muito freqüente e indife- 
reniemente aplicado de tais penas. Emite voto no sentido de que o legislador recorra o menos possível a estas penas e que os juízes tratem de aplicar, sempre que possível, medidas de ordem diferente, já existentes em vários países, tais como a condenação condicional, a liberdade vigiada ("épreuve" ou "probation"), a multa, a advertência judiciária, etc."

\section{Contra as longas penas de prisão}

Mas não se limitaram os congressistas a notar os inconvenientes da prisão curta. Chamaram também a atenção para as graves conseqüências das prisões longas. Assim, o próprio relator geral pontuava, na conclusão de seu trabalho:

"As prisões para a execução de longas penas apresentam, quase sempre, um equipamento insuficiente, tanto no que concerne ao pessoal como no que se refere a locais apropriados e "atéliers" necessários ao trabalho. O valor da formação profissional e da educação do caráter, que a pena de longa duração pode proporcionar, parece vir sendo exagerado. As dificuldades, que encontra todo aquêle que sofreu uma pena dessa natureza, para conseguir trabalho, quando de sua liberação, e meios para prover a própria subsistência, são fartamente conhecidas. Sua família fica quase sempre em situação econômica extremamente difícil, durante a sua parmanência no presídio."

Esses e muitos outros inconvenientes da prisão longa já se vêm fazendo sentir há bastante tempo, levando os legisladores a adotar medidas tendentes a diminuírlos. 0 mais vulgarizado é o da liberação condicional, instituto que adotamos e regulamentamos desde 1923 e que foi grandemente ampliado em 1940, de modo a permitir que se reduzam as prisões longas à metade, quanto aos delinqüentes primários, a três quartas partes, quanto aos reinci- 
dentes. E ao mesmo passo que, por via dêsse instituto do livramento condicional, se substitui quase que metade da duração das prisões longas pela liberdade vigiada, trata-se de fazer com que a prisão seja cada vez menos prisão.

\section{Modernização do regime presidiário}

O isolamento, que para os penitenciaristas do sistema pensilvânico seria o melhor fator de regeneração, encontra hoje repulsa generalizada, năo permitindo o nosso Código que êle seja superior a três meses. E tanto os congressos científicos como as assembléias legislativas vão inventando meios de tirar da prisão o caráter de instrumento de segregação social. Em lugar das prisões urbanas, muradas e gradeadas, constróem-se as penitenciárias agrícolas, nas quais desaparece a idéia de reclusão. $\mathbb{E}$ hoje estão na moda as chamadas prisões abertas, em que os condenados ficam presos pela palavra, isto é, por um compromisso de honra, e não pela brutalidade das muralhas intransponíveis e das grades de aço.

Chega-se mesmo à perfeição de ser dispensado até o serviço de guarda por policiais ou funcionários d'a administração pública. Nos Estados Unidos, rescindiram-se, com indenizações vultosas, contratos que a administração pú-blica havia firmado para a construção de penitenciárias segundo os planos de "major security", sendo substituidas por "farm-prisions" e pela organização de equipes de sentenciados para trabalhar na construção de estradas e até no serviço de extinção de incêndios nas florestas.

Na Califórnia, onde funciona a colônia agrícola de Chino, dormindo cêrca de 800 sentenciados em barracóes de aço transportáveis, e onde também trabalham várias turmas volantes em obras públicas, gastou o Estado, durante um biênio, apenas 76 dólares na recaptura de alguns 
raros fugitivos, ao passo que economizou vários milhões, deixando de construir prédios de cimento armado.

Informam Barnes e Teeters que o Govêrno da Pensilvânia rescindiu, em 1938, o contrato que havia feito para a construção da "Pennsylvania Alcatraz", que custaria mais de quatro milhões de dólares e que fôra planejada em regime de absoluta segurança, pagando cêrca de um milhão de dólares de indenização aos arquitetos. Em Nova York, ficou também sem acabar a "Green Heave» Prison", que estava orçada em sete milhões e setecentos mil dólares. E em um folheto publicado em 1942, pela New York Community Service Society, com o título de "Prisions Cost Too Much", essa penitenciária foi apontada como "an expersive monument on the wrong road." ("New Horizons on Criminology", ed. 1944, pág. 954.)

\section{As instituições abertas}

O Congresso Penal e Penitenciário de Haia tambén se manifestou sôbre uma tese relativa a êste assunto, concebida nestes têrmos:

“Dans quelle mesure les institutions ouvertes sont-elles appelées à remplacer la prison classique?"

Nümerosos estudos foram apresentadios, e a 2. ${ }^{a}$ Seção, em cujos debates tivemos ocasião de tomar parte, formulou uma definição de instituiçổes abertas e enumerou as suas vantagens, em sete substanciosos itens. Destacamos apenas os seguintes:

"Para os fins da presente discussão, consideramos que o têrmo "estabelecimento aberto" designa um estabelecimento penitenciário no qual as medidas preventivas contra a evasão não são constituídas por obstáculos materiais, tais como muros, fechaduras, grades ou guardas suplementares. A característica essencial de uma instituição aberta 
deve residir no fato de se exigir que os prisioneiros se submetam à disciplina da prisão sem uma fiscalização estreita e constante, consistindo o fundamento do regime em incutir no prisioneiro o sentimento da responsabilidade pessoal.

“As principais vantagens do sistema são as seguintes:

“a) melhoria da saúde tanto física quanto mental, dos sentenciados;

“b) as condições do internamento podem-se aproximar bem mais do gênero de uma vida normal do que as de um estabelecimento fechado;

“c) a tensão da vida penitenciária normal é aliviada e torna-se mais fácil manter a disciplina, raras vêzes havendo necessidade de penas disciplinares;

“d) a ausência de um aparelhamento físico de repressão e de aprisionamento, aparelhamento êsse substituádo pelas relações de confiança entre o prisioneiro e o pessoal, em vez de afetar a concepção anti-social dos internados, suscita condições propícias a um desejo sincero de readaptação;

“e) os estabelecimentos abertos são econômicos, tanto do ponto de vista das construções como no que concerne ao pessoal."

Aí temos, em todos os fatos que acabamos de enumerar e nessas conclusões do $12 .^{\circ}$ Congresso Penal e Penitenciário, a demonstração de que a prisão, na qual se concentra de modo principal a ação repressiva dos Códigos modernos, é uma pena que apresenta inconvenientes muito maiores do que as vantagens e contra a qual se volta a própria política criminal contemporânea, que procura por todos os meios e modos circunscrever os seus efeitos deprimentes sôbre a personalidade dos reclusos e trata de inventar subs- 
titutivos para essa espécie de panacéia do direito penal clássico.

\section{A noção de pena posta em cheque}

Olof Kinberg, o famoso professor da Universidade de Estocolmo, autor de uma série de livros sôbre direito penal e criminologia, entre os quais se destaca "Basic Problems of Criminology", publicado em 1935 e que desde 1936 vimos citando nesta Casa, relatou perante o Congresso de Criminologia de Paris a tese intitulada: "La Prison Facteur Criminogène." Nêsse trabalho, reafirma ainda uma vez a sua posição de antagonista da prisão como instrumento de combate ao crime e como meio de defesa social. Faz referência à lei sueca de 1945 , na qual os estadistas daquele país de instituições sociais modelares procuraram reduzir a prisão ao mínimo possível, criando escolas-prisões, estabelecimentos abertos de trabalho, tanto urbanos como rurais, substituindo as prisões curtas por multa e advertência, bem como pela liberdade vigiada. E não foge ao ataque de frente à pena em si mesma, como fazem Barnes e Teeters, e os numerosos pensadores e criminalistas citados pelos decididos autores de "New Horizons on Criminology". Como remate a tais considerações, diz o pensador sueco:

"Chega-se à conclusão de que a própria noção de pen” constitui obstáculo a uma política criminal racional e realista. Em lugar da noção de pena, é necessário colocar a noção de proteção: de um lado, proteção da gente honesta, contra os ataques criminosos; de outro lado, proteção contra uma evolução criminal nas pessoas que são impelidas para a delinqüência por sua própria natureza ou por circunstâncias compressoras.

"Eliminar a noção de pena do sistema de idéias que tem guiado até agora a política criminal prática equivale 
a produzir uma revolução de idéias. Mas as revoluções no mundo do pensamento produzem-se lentamente, quando não são impulsionadas por fortes mutações na vida econômica ou política. E' verdade que não faltam à política criminal aspectos econômicos, mas êles são pouco conhe-cidos do grande público. Sem temor de exagerar, poder-se-ia ao contrário sustentar que a política criminal constitui terra desconhecida para os políticos; e daí a convicção de que a noção de abolição de pena, na política criminal, será ainda demorada.

"Entretanto, é necessário fazer algo para melhorar o atual estado de coisas, que verdadeiramente não é satisfatório. Foi o que fizemos em nosso país, pela lei sôbre a execução d'a pena, votada em 1945. Seu traço fundamental está numa redução das medidas que limitam a liberdade de ação dos internados."

\section{Proposições radicais}

Passa depois Olof Kinberg a descrever as medidas adotadas naquele país, para que a prisão ofenda o menos possível a liberdade e sobretudo o sentimento de dignidade humana, que deve ser reavivado e fortificado, quanto possível, em todos os sentenciados. E termina oferecendo ì consideração dos congressistas duas proposições radicais para a transformação da política criminal, acompanhadas de outras, para o estado transitório de transformação panlatina do sistema penal em sistema de tratamento benérico dos criminosos, capaz de propiciar a readaptação do maior número possível à comunidade social.

As proposições radicais são estas:

"1." Para criar uma política criminal realista e racional, é necessário eliminar da mesma todo elemento metafísico. 
" 2 . $^{a}$ O conceito de pena retributiva, sendo um conceito impregnado de emoções de ordem metafísica, consiitui um obstáculo à realização de uma política criminal efetiva, e por isso deve ser eliminado."

Ali temos o grande criminalista nórdico, informado pelo pensamento de um dos palíses de maior progresso nas ciências e nas realizações sociais, a salientar, em 1950, a contradição entre as finalidades que os penalistas e os estadistas, desde o fim do século passado, procuram atribuir à pena c tratam de realizar pelos sistemas penais que têm sido baldadamente experimentados. Se o tratamento criminal deve ter como finalidade a reeducação do delinqüente e a sua recondução ao meio social, é preciso escoimar êsse tratamento de medidas que dificultem a realização dêsse desiderato. A pena, especialmente a de prisão, produ $z$ uma degradação da personalidade e traz consigo uma série de conseqüências, cad'a qual delas mais prejudicial aos objetivos fundamentais de reeducação e de criação de hábitos sociais em criaturas que já demonstraram certa tendência para a vida anti-social.

Charles Dickens, depois de visitar, em 1842, a Penitenciária de Filadélfia, onde se observava o regime de isolamento, mostrou-se horrorizado com aquêle processo de desagregação da própria alma d'os indivíduos. Considerou aquêle verrumar lento e diário dos mistérios do cérebro um mal incomensuràvelmente pior do que tôdas as torturas físicas. Parecia-lhe que nada de saudável e de bom poderia criar essa solitude tão contrária à natureza, e acrescentou que até um cachorro se sentiria acabrunhado: e embrutecido sob a sua influência.

Três quartos de século foram necessários para convencer os penalistas, derribando-se a última Bastilha do sistema pensilvânico, representada pelas prisões da Bèl.gica, que só se tranformaram depois da passagem de Vandervelde pelo Ministério da Justiça. Mas a prisão continua 
a ser o remédio principal da terapêutica penal de nossos dias. E se o misticismo dos "quakers" não conseguiu tirar: do isolamento os resultados miríficos que se atribuíam às células conventuais, verifica-se que também não conseguem os estadiastas modernos transformar êsses centros de promiscuidade, que são as prisões contemporâneas, em se-minários de vida social.

O professor Frank Tannenbaum, da Universidade de Colúmbia, lançou, em 1942, o seguinte anátema contra a prisão: "We must destroy the prison, root and branch."

E o professor John L. Gillin escrevia em 1931:

"Que monumento de estupidez são essas instituições que nós construímos - estupidez não tanto dos reclusos como dos cidadãos livres! Que zombaria da ciência, a nossa disciplina das prisões e essa mole de iniqüidade social nas prisões - o bom e o mau unidos num estupendo "pot-pourri"! Que rematada tolice, essa de pensar que se podem preparar homens para a vida social subvertendo o processo ordinário de socialização: silêncio para o único animal que fala; regulamentação repressiva para homens que estão na prisão porque necessitam aprender a exercitar suas atividades de maneira construtiva; artificiosa conformidade a regras que reprimem todo esfôrço de expressão construtiva; trabalho sem o estímulo de motivos econômicos; atuação pelo mêdo da punição, em vez da esperança de recompensa ou dả invocação de sentimentos elevados; servilismo, em vez de nobreza; recompensas asseguradas pela traição a um companheiro, em vez do desenvolvimento de uma franca lealdade!" (Barnes e Teeters, op. cit., pág. 494.)

\section{O direito protetor}

Em vez de continuarmos nessa tentativa impossível de reabilitar instituições que nasceram erradas, melhor 
seria abraçarmos desde logo, e sem temores, a doutrina de Dorado Montero do direito protetor dos criminosos, e organizar estabelecimentos cuja freqüência jamais pudesse constituir para alguém um estigma de degradação. Enquanto nos hospícios se martirizavam os loucos, para livrá-los do demônio, inspiravam êsses estabelecimentos $a$ mesma repugnância das prisões da atualidade; depois da revolução operada pela psiquiatria de Pinel, os hospícios se transformaram em sanatórios. Deixaram de ser antros apavorantes de dor e castigo, para serem abrigos onde a desgraça encontra linimento.

Quando os estabelecimentos para tratamento de delinqüentes tiverem passado por uma metamorfose igual, estarão aplainadas tôdas as dificuldades que hoje se levantam contra a aplicação de medidas de segurança sem delito. As restrições que se impuserem à liberdade tanto daqueles que se acham em estado perigoso como dos que já cometeram infrações estarão isentas de tôda e qualquer idéia de retribuição do mal pelo mal e de degradação do criminoso. Quem passar por um estabelecimento dêstes não sairá mais como um réprobo, marcado por um estigma de inferioridade social.

$\mathrm{E}$, assim, se tornará mais fácil o seu encaminhamento para as atividades condizentes com seus interêsses, com o bem-estar de sua família e com os altos desígnios da vida em sociedade. 